\title{
Smart Performance Measurement Tool In Measuring The Readiness of Lean Higher Education Institution
}

\author{
Okfalisa \\ Department of Informatics Engineering \\ UIN Sultan Syarif Kasim Riau Indonesia \\ okfalisa@gmail.com
}

Wresni Anggraini

Department of Industrial Engineering

UIN Sultan Syarif Kasim Riau Indonesia

wreni_anggraini@ymail.com

\author{
Fitri Insani \\ Department of Informatics Engineering \\ UIN Sultan Syarif Kasim Riau Indonesia \\ fitri.insani.03@gmail.com
}

\author{
Rahmad Abdillah \\ Department of Informatics Engineering \\ UIN Sultan Syarif Kasim Riau Indonesia \\ rahmad.abdillah@uin-suska.ac.id
}

\author{
Saktioto \\ Department of Physics \\ Universitas Riau Indonesia \\ saktioto@yahoo.com
}

\begin{abstract}
The development of autonomy University drives management innovation to increase the alternative sources of income with the purpose of the efficiency improvement and productivity of the institution. One of a management model that leads to increase productivity through cost reduction is Lean service. The implementation of Lean Higher Education Institution (LHEI) requires total involvement of organization maneuver, including social culture, infrastructure, and leadership support. Therefore, the readiness of the institution in welcoming Lean concepts becomes significant. This article tried to develop a prototype of an intelligent performance measurement tool by analyzing the readiness indicators using the Analytical Hierarchy Process (AHP) method. This tool provided the classification of organizational readiness into five performances level. The measurement performed as a Decision Support System (DSS) to recommend University management level in making a decision and correcting action towards the optimal execution of Lean service. As a case study, this prototype system has been tested with Black Box and User Acceptance Test (UAT) in Indonesia Islamic Higher Education Institution. The finding reveals that the prototype system can be used as a performance measurement tool in measuring the readiness of Lean's service in Islamic Higher Education Institution.
\end{abstract}

Keywords-Performance Measurement Tool, Lean Higher Education Institution, Lean Service Model, Decision Support System, Analytical Hierarchy Process.

\section{INTRODUCTION}

The education world plays as an essential factor in determining the success of a country. Compared to other Southeast Asian countries, the allocation of education funds in Indonesia is despicable. As a matter of fact, the higher education budget in Indonesia has decreased significantly that reaching a cut rate of $12.8 \%$ in 2015 and 2016. Economical condition and government policy demand encouraging university in finding an alternative source of budgetary as well as increasing the education price. This coerces the autonomy university to suppose more responsiveness and competitiveness in the direction of commercialization and industrial needs. The creative innovation within management institutional is necessary particularly with regard to the organizational strategy and financial that supports the efficiency and productivity of the institution. Management optimization, planning capacity, and efficiency can be done through the reduced costs and aligning the productions into market demands.

In order to answer above phenomenon, various approaches have been introduced for the scope of higher education, including Total Quality Management (TQM) [1], Six Sigma, Servqual [2] and Agile [3]. However, with regards to the success of the optimization method, the Lean concept has proven to be the best approach [4] and [5]. Lean service can be defined as an approach that can improve organizational performance through the lowest cost quality improvement [6]. This model creates an effective process of management, low cost, customer satisfaction, spirit of team as well as organizational culture development, flexible and responsive knowledge management, value chain, and organizational integration and networking.

The success of Lean services in manufacturing and private companies has encouraged the emergence of ideas to employ this concept in the education sector. Many higher education institutions have been tried to apply Lean concept. [7] put into practice the Lean concept at Albeda College in the Netherlands. It found that Lean HEI services can be enhanced through the improvement of communication, directly or technologically bases. Several leading universities in America attempted to enforce the concept despite facing the unsatisfaction result [8]. Similar cases turned out in several business schools and universities in the United Kingdom [9]. Generally, the study of Lean HEI carried out on operational sector, viz. academics, communication, management financial, learning system, curriculum, facilities, and virtual libraries [10], [11], [12], and [13]. The high dependency on government budget caused the limited enthusiasm of university in applying the Lean concept. In addition, the tendency of major resistant of organizational culture over the changes and innovation, the limitation of capacity and capability building of management over the changes, and the lack of decision makers support become the obstacles in making the execution of Lean concept success. Therefore, the readiness of institution transforms into a successful benchmark of Lean HEI execution. Stand from the Kaizen concept [6] as the basic philosophy of Lean HEI, this paper tried to study the 
measurement of HEI readiness into the development of smart performance measurement tool. The readiness was appraised by considering the influencing quality indicators as criteria in the functioning of academia and their success in achieving objectives of educational activities. Education provides an academic service as well as research and teaching that closely faced in conflict. The value concept is complicated and hard to be measured. This is due to the involvement of intangible factors regarding on the knowledge creation and dissemination [5], and responsible for preparing students into the development of active learning society [14], experts and future leaders [15]. On the other side, the budget cuts provoked a big pressure, exposing the need to reformulate and manage the resources based on the demand.

Comparing to other methods, the Analytical Hierarchy Process (AHP) is more effectively used to analyze the importance of the performance criteria of a measurement project [16]. AHP commonly utilizes Multi-Criteria Decision Making (MCDM) for solving semi and un-structured problems. It combines the qualitative and quantitative assessment method to overcome the shortcoming of a single measurement [17]. The application of AHP in measuring the performance in many platforms has been reviewed, including in education, Supply Chain, Virtual Learning, and manufacturing companies [18],[19], and [20]. Moreover, the integration of this method with other performance measurement tool such as Balanced Scorecard was also defined earlier [21] and [22]. AHP through the forming pairwise comparison matrix is capable to generate the increase of redundancy and reduce some errors. However, several $\mathrm{P}$ limitations regarding the number of comparisons and environment analysis were brought about the restriction of AHP in specifications and rules [23].

Advancing the mechanism of performance measurement tool, this paper delivered AHP as a smart management model in measuring the multi-criteria decision making with a view towards the readiness of Lean execution. Qualitative and quantitative perceives from internal and external stakeholders involved were taken into account in AHP. Customization of indicators' weight put forward this tool as intelligent services and supported decision-making system in performance measurement. The graphical analysis of indicators performance aided the decision makers to understand well their readiness and take the corrective action towards the maximal achievement. The management of knowledge base technology in this prototype tool allowed the more convenient way for HEI in analyzing the obstacles and constraints of Lean services in the direction of success. The possible risks and failures during the execution can be minimized and tracked earlier. A prototype system of this smart performance measurement tool was designed and tested in Black box and UAT. A case study in Faculty Sains and Technology UIN Suska Riau was conducted in measuring the readiness of 5 departments in delivering the Lean services concept.

\section{LITERATURE REVIEW}

\section{A. Lean Service in Higher Education Institutions}

Towards the practice of Lean in HEI, several considerations must be a focus on [15] and [24], including the optimization of the activity flow in production or services and the possible effector action in achieving the success; the awareness of an organization on the role of technology in supporting the effective process in production and services thus seamless transfer and access to seasonable data and information; the optimization of human resources capability and utilization; the development of innovation in integrated products and services teams; introduction on the significant of trust and commitment in developing the relationship within organization; managing and stay focusing on the sustainability of customers; developing the lean thinking of organizational culture across management levels; developing the sustainability of innovation and improvement process; maximizing the sustainability of environment against the changes. Once an HEI decides to implement the Lean concept, the readiness in facing the emergence of initiatives as well as the culture changes, the effectiveness of the institutional process, and the efficiency used of resources in the delivery of high-quality services become a hazard. In HEI, there were three core processes that targeted the lean initiatives, viz. teaching process, research process, and communication process [15]. The lean eliminates waste and makes the processes above more efficient and providing better value to the customers. Based on the literature reviews and interviews, this paper identified some indicators in dimensioning the readiness of HEI in the core processes that transfigured into four Lean constructs.

\section{1) People Waste $(\mathrm{PW})$}

People waste explained the squander of activities with regards to the knowledge, skills, ability, and competencies of stakeholders on teaching, research, and communication process in this case study. It is discovered some facts that many staffs and lectures' knowledge and competencies far from the expectation, the passive students was figured out during the class activities, the high planned curriculum achievement compared to the available of skill and knowledge provided, the lack of management controls on students' progress activities, inadequacy collaboration amongst students and lectures for the purpose of high quality research and publication, and the burned out and disheartened staff and lectures in downstream activities due to the insufficiency management of upstream knowledge and capability. Accordingly, the readiness of lean was holding an inquiry in reliance on the employment of lectures as per qualification (PW1); the capable of students and lectures in supporting the development of creative and active learning (PW2); regularly monitoring and evaluation of updated and standards curriculum and achievements (PW3); the collaboratively of management controls on students and lecturers' research development and any progress activities (PW4); the affection of rewards and promotion system in encouraging the potential development of students, staff and lectures (PW5).

\section{2) Asset Waste (AW).}

Asset waste was elucidated the effective utilization of organizational resources. It was determined the circumstances of poor planning curriculum, materials, instruments, and any resources facilities for teaching, research, and synergism; 
failure to meet scope and target thus missing the alignment of vision and mission translated; various un-solved problems, obstacles, challenges thus losing out the facing opportunities; the lack a sense of ownership and the responsibility of students, lectures, and staffs on sustainability of educational asset. Therefore, the readiness was appraised by some criteria, including the availability of sufficient and standardizes training facilities for students, lectures, and staffs in order to increase their knowledge and competency (AW1); the availability of sufficient facilities in line with the latest technology in assistance the teaching, research, and communication processes (AW2); the availability of mechanism and information technology for asset management (AW3), and the adjudication of external stakeholders on university output and services (AW4).

\section{3) Process Waste (PsW)}

Process waste was observed the un-sufficient of procedure and administrative thus inhibits the success, such as the lacking of operational standards on administration services for students, lecturers, and staffs in such a way the messy administration and un-controlled cannot be avoided; the elevated requirements and procedures of final project obstructed the students to graduate on time, the intervention within the admission process caused the deterioration of students quality. Hence, the willingness towards Lean implementation was gauged by the availability of procedure operational standard for the entire administration services in teaching, research, and communication activities (PsW1), the availability of procedure operational standard for students, lectures, and staffs admission in ensuring the proper quality of them (PsW2), the upstream management support in ascertaining the success flow of procedure operational standard (PsW3), the availability of policies in coming to the aid the effective and efficiencies process (PsW4), the availability of reference qualification standard on process activities (PsW5), and a sense of ownership on work process responsibilities (PsW6).

\section{4) Information Waste (IW)}

Information waste was identified the un-explored utilization of information, particularly with regards on students and lecturers' knowledge and capability in corroborating active learning and partnership research innovation, the lack of information and knowledge acquisition during the curriculum progression that considered the competitive advantages, market industrial demands, and technology disruptions. Therefore, the sufficient of curriculum in fulfilling the competitive advantages, market industrial demands and technology disruptions (IW1), the level competency of students, lectures, and staffs in teaching, research, and communication (IW2), and the capability of students, lectures, and staffs in knowledge acquisition and information filtering (IW3).

\section{5) Lean HEI consideration (LHEI)}

This concerned on the awareness of organizational on the significant of lean implementation and identified the potential obstacles and challenges. The measurement focused on some aspects, viz. the awareness level of HEI community environment on lean (LHE1), the understanding level of community on lean implementation (LHE2), the leadership support on the lean execution (LHEI3), and the complexity level of procedure in activating the lean HEI (LHEI4).

\section{Methodology}

The methodology applied in this paper was divided into two stages (See Fig.1). The first stage was related to the formation of a conceptual model, while the second stage was emphasized on the design of smart performance measurement tool in terms of the DSS system. The conceptual model was assembled through thorough reviews of some journals, books, and papers. The conduction of interviews with a number of relevant stakeholders such as dean, deputy dean, head of departments, senior lectures, students, and faculty and departments staffs attested lean model development in HEI. Accordingly, 4 constructs and twenty-two indicators were then transcribed into instrument construction. As the utilization of AHP in analyzing performance, 2 kinds of questionnaires were delivered. Nine top management levels in faculty and department were asked their level importance of indicators in AHP. The dynamic weighting management presented flexible indicators and constructs appertaining to preferences. Meanwhile, the readiness measurement was tallied in reference to the dissemination of questionnaire 2. The respondents from the top and middle management level in faculty and department were questioned. Several senior lectures, staffs, and students finalized the analysis of this instrument. In addition, the external stakeholders from alumnus, companies, government officers and parents also contributed. Hence, the level performance was grouping into 5 categories and presented the graphical information analysis of each indicator and constructs. This measurement delivered a valuable and detailed recommendation as corrective action towards maximal achievement. To automate the listing process of performance measurement,the design of the prototype system was cultivated. This system smartly configuration with the concept of DSS integrated AHP as model management components. The rule of knowledge management was evolved in accordance with AHP step process. In addition, the interactive interface was designed to aid the decision makers in setting the priority weight in measuring the preparedness of lean implementation. The waterfall model was put into practice as a software development life cycle. Black-box and UAT test validated and confirmed this system.

\section{RESULT AND ANALYSIS}

\section{1) DSS-AHP Analysis}

\section{a) Hierarchy structure}

DSS-AHP modeled the framework into criteria, subcriteria, and alternatives. Five domain criteria with total twenty two indicators included People Waste (PW) - PW1, PW2, PW3, PW4, and PW5; Asset Waste (AW) - AW1, AW2, 
AW3, and AW4; Process Waste (PsW) - PsW1, PsW2, PsW3, PsW4, PsW5, and PsW6; Information Waste (IW) - IW1, IW2, and IW3; and Lean HEI consideration (LHEI) - LHEI1, LHEI2, LHEI3, and LHEI4. The definitions and scopes of each criteria were explained in the chapter literature reviews. The classification of five performance grouping was scaled into "Bad" (0\%-19.99\%), "Not Good" (20\%-39.99\%), "Enough" (40\%-59.99\%), "Good" (60\%-79.99\%), "Very Good" (80\%-100\%). The hierarchy structure for Lean Model in HEI was portrayed in Fig. 2.

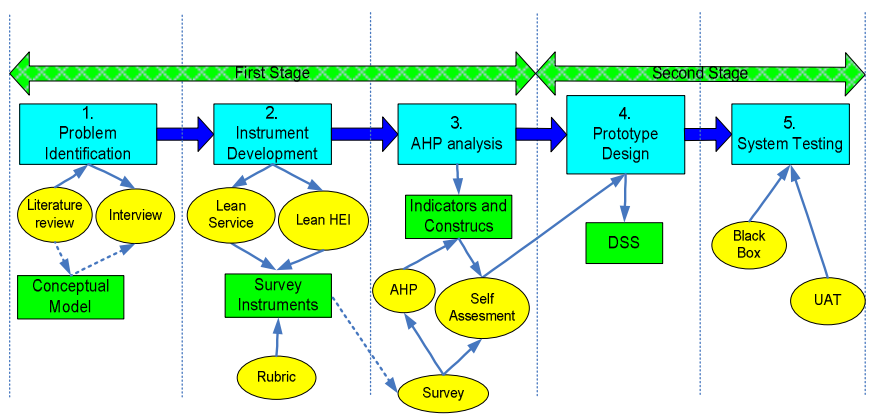

Fig 1. Methodology Schema

\section{b) Priority weight analysis}

Priority weight of indicators was calculated by the paired matrices comparison, matrices normalization, the eigenvector calculation, and the testing of Consistency Index (CI) and Consistency Ratio (CR) accepted values $<10 \%$. The questionnaire 1 generally analyzed the level importance of indicators from 9 scale AHP performance thus confirmed the priority weight and consistent approved. As a result, persistent indicators can be admitted. Detailed information was explained in Table 1.

The table described that Asset Waste (AW) as the most priority constructs in measuring the readiness of lean with the list priority weight for indicators were AW5, AW3, and AW4, respectively. LHEI delivered as secondary priority thus itemized indicators were LHEI1, LHEI2, LHEI3, and LHEI4, respectively. The third priority constructs were IW with tabulated indicators were IW1, IW2, and IW3, respectively. Next constructs were PsW in the listed indicators were PsW1, PsW2, PsW3, PsW4, PsW5, and PsW6, respectively. Finally, the least priority constructs were $\mathrm{PW}$ with detailed indicators in PW5, PW3, PW4, PW1, and PW2, respectively.

\section{c) The measurement of lean readiness}

The analysis of questionnaire 2 revealed the operational work of the model thus presented in Fig. 3. The performance was grouping according to the priority weight calculation in questionnaire 1 and respondents' answers in questionnaire 2 with resulted in $68.11 \%$ as "Good" performance (See Table 1 column performance calculation). In order to break up indicators performing, the blue lines in Fig. 3 were offered an explanation. Herein, the performance of Asset Waste (AW) became the highest constructs with indicators achievement level in AW1, AW2, AW3, and AW4, respectively. Hence, it was followed by constructs Information Asset (IW) and Lean HEI (LHEI), Process Waste (PsW), and People Waste (PW), respectively. Comparing to the red lines as maximal performance, the achievement of Faculty Science and Technology was still far from expectation. Thus the readiness of this faculty on lean execution must be explored more and increased, especially for priority indicators. This analysis recommended the decision makers in making a decision and corrective action on lean readiness.

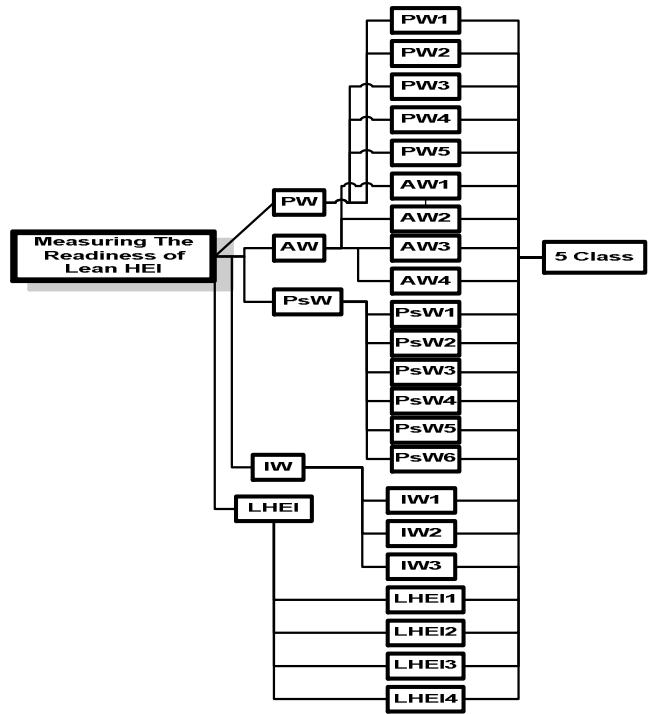

Fig. 2. Hierarchy Structure Lean HEI

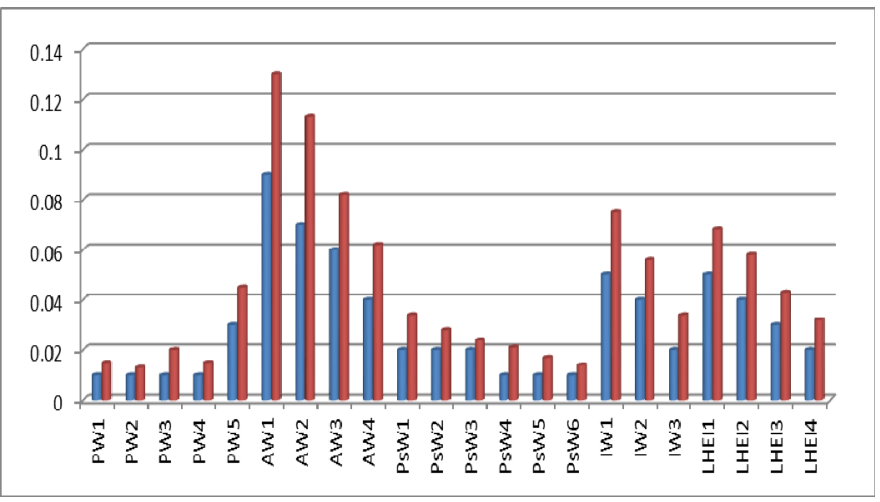

Fig. 3. Case Study Performance Measurement 
TABLE I. THE RESUME OF MODEL PRIORITY WEIGHT

\begin{tabular}{ccccccccc}
\hline Indicators & Mean & Constructs & CI & CR & $\begin{array}{c}\lambda \\
\max \end{array}$ & $\begin{array}{c}\text { Construct } \\
\text { Weight }\end{array}$ & $\begin{array}{c}\text { Eigen } \\
\text { Vector }\end{array}$ & $\begin{array}{c}\text { Performance } \\
\text { Calculation }\end{array}$ \\
\hline PW1 & 0.69 & & & & & 0.015 & 0.01 \\
PW2 & 0.78 & Process & & & & & 0.013 & 0.01 \\
PW3 & 0.72 & Waste & 0.038 & 0.034 & 5.153 & 0.108 & 0.020 & 0.01 \\
PW4 & 0.7 & (PW) & & & & & 0.015 & 0.01 \\
PW5 & 0.75 & & & & & 0.045 & 0.03 \\
AW1 & 0.66 & Asset & & & & & 0.130 & 0.09 \\
AW2 & 0.65 & Waste & 0.004 & 0.005 & 4.013 & 0.388 & 0.113 & 0.07 \\
AW3 & 0.69 & (AW) & & & & & 0.082 & 0.06 \\
AW4 & 0.67 & & & & & 0.062 & 0.04 \\
PsW1 & 0.65 & & & & & 0.028 & 0.02 \\
PsW2 & 0.73 & Process & & & & & 0.024 & 0.02 \\
PsW3 & 0.72 & Waste & 0.070 & 0.056 & 6.351 & 0.138 & 0.021 & 0.01 \\
PsW4 & 0.65 & (PsW) & & & & & 0.017 & 0.01 \\
PsW5 & 0.67 & & & & & 0.014 & 0.01 \\
PsW6 & 0.67 & & & & & 0.075 & 0.05 \\
IW1 & 0.65 & Information & \multirow{2}{*}{0.023} & 0.040 & 3.047 & 0.165 & 0.056 & 0.04 \\
IW2 & 0.75 & Waste (IW) & & & & & 0.034 & 0.02 \\
IW3 & 0.72 & Lean & & & & & 0.068 & 0.05 \\
LHEI1 & 0.67 & Higher & & & & & 0.058 & 0.04 \\
LHEI2 & 0.65 & Education & 0.004 & 0.005 & 4.013 & 0.201 & 0.043 & 0.03 \\
LHEI3 & 0.69 & Institution & & & & & 0.032 & 0.02 \\
LHEI4 & 0.67 & (LHEI) & & & & & Performance Measurement : & $68.11 \%$
\end{tabular}

\section{2) DSS-AHP Prototyping Design}

\section{a) Architecture Design}

To automate the entire measurement and AHP calculation, a prototype system of DSS-AHP was constructed as shown in Fig.4. Top and middle managers sides submitted their answers in questionnaire one and two as well as the customization of priority weight founded on the Lean model. In the meantime, a performance measurement survey in questionnaire two was disseminated to external and internal stakeholders with a view toward the appraisement of lean readiness. The response was analyzed in data management towards the deliberation of the AHP model. The criteria, the paired matrices comparisons, and the weighted priority were formulated to root cause alternatives chosen.

Herein, the knowledge-based system and organizational knowledge-based were considered in managing the rules to possible alternatives. Finally, the system interface proposed the graphical information regards to the readiness performance measurement in forms of 5 classes. The system presented the quantification together with detailed analysis of indicators and constructs.

\section{b) System Testing}

Black Box testing identified that the functionality of system and procedures run properly as stated in the expected input and output. UAT test from fifty respondents verified the friendly used, interactive, accepted interface design, and the advisability of the system with $93 \%$ of satisfaction.

\section{CONCLUSION}

The construction of the lean model in teaching, research, and communication for Higher Education Institution has been successfully carried out. Five constructs with twenty-two indicators were defined as considered criteria in weighing the readiness of lean realization in an academic platform. Smartly performance measurement tool was flying colors designed by adopting DSS-AHP. This method bravely explained the qualitative and quantitative analysis through the customization of priority weight and the series stages of AHP calculation. Level performance achievement was grouped into 5 classes thus explicated the actual willingness lean condition in HEI. Design of intelligent prototype system was successfully created in computerizing the AHP activities as a performance measurement tool. System testing brought about the sufficiency of this prototype in prompting the decision makers in the direction of lean implementation success.

\section{ACKNOWLEDGMENT}

We would like to thanks to UIN Suska Riau, Indonesia as sponsorship and our team members in Department Informatics, Faculty of Science and Technology. The contribution of external and internal stakeholders was really appreciated in creating the success of this research. Many thanks for your cooperation and support. 


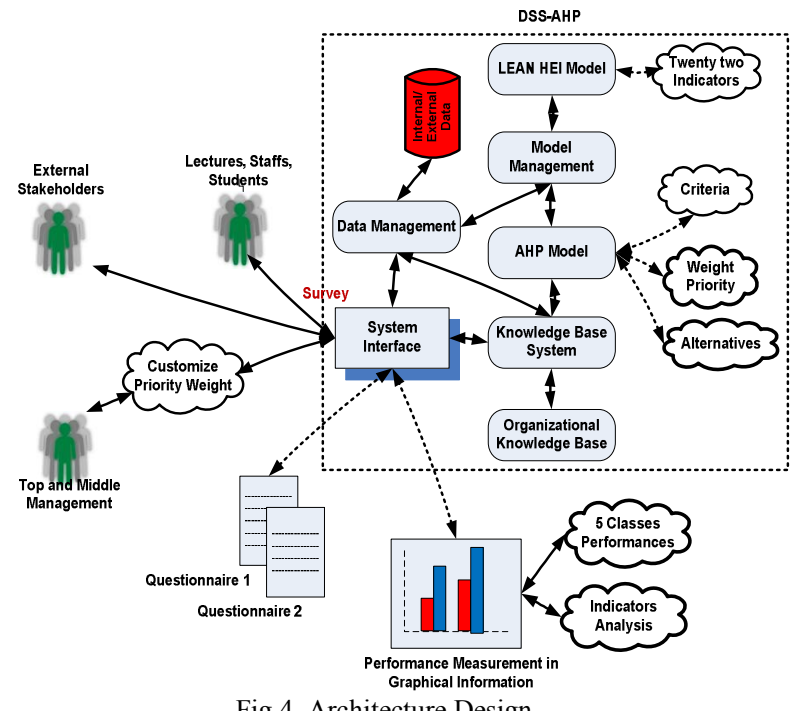

Fig.4. Architecture Design

\section{REFERENCES}

[1] J. W. Dean and D. E. Bowen, "Management Theory and Total Quality: Improving Research and Practice through Theory Development," Acad. Manag. Rev., vol. 19, no. 3, p. 392, Jul. 1994.

[2] A. Parasuraman, V. A. Zeithaml, and L. L. Berry, "SERVQUAL: A multiple item scale for measuring consumer perceptions of service quality," J. Retail., vol. 64, no. 1, pp. 12-40, 1988.

[3] M. Hallgren and J. Olhager, "Lean and agile manufacturing: external and internal drivers and performance outcomes," Int. J. Oper. Prod. Manag., vol. 29, no. 10, pp. 976-999, Sep. 2009.

[4] Z. Radnor, P. Walley, A. Stephens, and G. Bucci, "Evaluation of the lean approach to business management and its use in the public sector," Edinburgh, 2006.

[5] N. A. Okfalisa, R. A. Alias, K. Y. Wong, and S. C. Chong, "A knowledge management metrics model for measuring strategy implementation success," Int. J. Bus. Excell., vol. 5, no. 4, p. 305, 2012.

[6] J. P. Womack and D. T. Jones, Lean Solutions: How Companies and Customers Can Create Value and Wealth Together. New York: London: Free Press, 2005.

[7] T. Van Der Wiele, "Quality management in a teaching organization,” Total Qual. Manag., vol. 6, no. 5, pp. 497-508, Dec. 1995.

[8] W. K. Balzer, Lean Higher Education: increasing the value and performance of university processes. Boca Raton; London: CRC Press, 2010.

[9] Z. Radnor and G. Bucci, "Analysis of Lean Implementation in UK Business Schools and Universities," 2011.

[10] A. S. Bargerstock and S. R. Richards, "Case study: application of DMAIC to academic assessment in higher education," Qual. Approaches High. Educ., vol. 6, no. 2, pp. 31-40, 2015.

[11] W. W. Fisher, S. Barman, and P. L. Killingsworth, "Value stream mapping for improving academic advising," Int. J. Inf. Oper. Manag. Educ., vol. 4, no. 1, p. 45, 2011.
[12] J. P. Lorenzetti, "Using 'lean'processes in distance education," Distance Educ. Rep., vol. 18, no. 6, pp. 3-4, 2014.

[13] M. F. M. Isa and M. Usmen, "Improving university facilities services using Lean Six Sigma: a case study,” J. Facil. Manag., vol. 13, no. 1, pp. 70-84, Feb. 2015.

[14] Okfalisa and A. H. Harahap, "Implementasi Metode Term Frequency-Inverse Document Frequency (TF-IDF) Dan Maximum Marginal Relevance Untuk Monitoring Diskusi Online," Univ. Islam Negeri Sultan Syarif Kasim, vol. 13, no. 2, pp. 151-159, 2016.

[15] A. Qayyum and I. Manarvi, "IMPLEMENTATION OF LEAN THINKING IN HIGHER EDUCATIONAL INSTITUTIONS (HEIS)," in INTED2017 Proceedings, 2017, vol. 1, no. March, pp. 699-710.

[16] H. Fu and S. Lin, "Applying AHP To Analyze Criteria of Performance Measurement for National Energy Promotion Projects," Int. J. Electron. Bus. Manag., vol. 7, no. 1, pp. 70-77, 2009.

[17] J. Zhang and X. Zhang, "The application of AHP in performance evaluation of ideological and political education in colleges and universities," in Proceedings of the 2nd International Conference on Management Science and Industrial Engineering (MSIE 2013), 2013, no. Msie, pp. 566-569.

[18] M. Ramaa, T. M. Rangaswamy, and K. N. Subramanya, "AHP Based Performance Measurement System of Supply Chain," Glob. J. Manag. Bus. Res., vol. 10, no. 5, pp. 150309-150305, 2010.

[19] W. Ho, H. E. Higson, P. K. Dey, X. Xu, and R. Bahsoon, "Measuring performance of virtual learning environment system in higher education," Qual. Assur. Educ., vol. 17, no. 1, pp. 6-29, Jan. 2009.

[20] M. Yurdakul * and Y. T. İÇ, "Development of a performance measurement model for manufacturing companies using the AHP and TOPSIS approaches," Int. J. Prod. Res., vol. 43, no. 21, pp. 4609-4641, Nov. 2005.

[21] O. Okfalisa, S. Anugrah, W. Anggraini, M. Absor, S. S. M. Fauzi, and S. Saktioto, "Integrated Analytical Hierarchy Process and Objective Matrix in Balanced Scorecard Dashboard Model for Performance Measurement," TELKOMNIKA (Telecommunication Comput. Electron. Control., vol. 16, no. 6, p. 2703, Dec. 2018.

[22] H. R. Feili, N. Vasheghani Farahani, and N. Vesaghi, "Integration Of Fuzzy Analytic Hierarchy Process (FAHP) With Balance Score Card (BSC) In Order To Evaluate The Performance Of Information Technology In Industry," J. Math. Comput. Sci., vol. 02, no. 02, pp. 271-283, Feb. 2011.

[23] J. M. Fernandes, S. Prozil Rodrigues, and L. A. Costa, "Comparing AHP and ELECTRE I for prioritizing software requirements," in 2015 IEEE/ACIS 16th International Conference on Software Engineering, Artificial Intelligence, Networking and Parallel/Distributed Computing (SNPD), 2015, pp. 1-8.

[24] C. L. Comm and D. F. X. Mathaisel, "Less is more: a framework for a sustainable university,” Int. J. Sustain. High. Educ., vol. 4, no. 4, pp. 314-323, Dec. 2003. 